See discussions, stats, and author profiles for this publication at: https://www.researchgate.net/publication/263688439

\title{
Developing inclusive environments in mental health provision for people
} with disabilities

Article in Journal of Mental Health Training · June 2013

DOI: 10.1108/JMHTEP-07-2012-0021

CITATIONS

2

2 authors:

Graham Whitehead

London Metropolitan University

2 PUBLICATIONS 2 CITATIONS

SEE PROFILE
35

dam Barnard

Nottingham Trent University

15 PUBLICATIONS 27 CITATIONS

SEE PROFILE

Some of the authors of this publication are also working on these related projects:

Project Knowledge Transfer Partnership View project 


\title{
Developing inclusive environments in mental health provision for people with disabilities
}

\author{
Graham Whitehead and Adam Barnard
}

Graham Whitehead and Adam Barnard are based at the School of Social Sciences, Nottingham Trent University, Nottingham, UK.

\begin{abstract}
Purpose - The increased use of mental health interventions employing cognitive behavioural therapy (CBT) over the last decade raises the significant theme of the efficacy of such treatments for people with disabilities. Recent evidence-based studies regarding the application of cognitive behavioural interventions for people with disabilities have highlighted issues concerning access to services, questions of engagement and efficacy of the cognitive aspects of CBT practice and service models and forms of delivery. The purpose of this paper is to explore these themes with particular emphasis on barriers to accessibility for this population and provide consideration of ethical and effective practice aspects of psychological interventions in response to the recent World Health Organisation recommendations on disability provision.

Design/methodology/approach - The paper considers the development of the "enabling environments" theme for people with disabilities within a mental health context within Europe, with a view to exploring barriers to social inclusion and service user autonomy. The paper is designed to review and enhance existing literature in the field and to question the philosophical position of cognitive-behavioural approaches to mental health provision in a European context.

Findings - Consideration is given to the use and application of CBT and evidence-based practice (EBP) and considers efficacy in mental health provision for this population. Consideration is also given to the efficacy and appropriateness of short-term interventions for this population.

Research limitations/implications - As a conceptual paper, the limitations of the discussion are that the views expressed are solely those of the authors but the paper usefully develops consideration of the existing literature in the field and discusses the implications of developing inclusive practice in mental health provision for this population.

Practical implications - The issues discussed in the paper offer significant questions relevant to the delivery of mental health provision for people with disabilities from a European perspective. Practical implications relate to the development of inclusive practice for practitioners in the delivery of these services. Social implications - The social implications of the paper are significant, as the issues discussed raise questions about how mental health services approach their provision for people with disabilities. From a social context, the conceptual discussion offers insights useful to develop effective mental health provision and promote service user responsibility and autonomy.

Originality/value - As a conceptual paper, the originality of the submission relates to questioning the efficacy of more recent developments in the mental health field re: philosophy of approach and method and recommendations are offered by the authors which may impact service delivery, the focus of relevant evidence-based practice and service user autonomy.
\end{abstract}

Keywords Disabled people, Mental Health services, Europe, Inclusion, Enabling environments, Short-term interventions, Cognitive-behavioral therapy, Evidence based-practice

Paper type Conceptual paper

\section{Introduction}

The increased use of cognitive behavioural models in mental health interventions over the past decade in the EU member states raises the question of the appropriateness and efficacy of

DOl 10.1108/JMHTEP-07-2012-0021 VOL. 8 NO. 2 2013, pp. 103-111, @ Emerald Group Publishing Limited, ISSN 1755-6228 $\mid$ THE JOURNAL OF MENTAL HEALTH TRAINING, EDUCATION AND PRACTICE | PAGE 103 
such treatments for people with disabilities. Evidence-based studies have highlighted specific themes which may impact the efficacy of mental health interventions for some people with disabilities, for example, possible questions of engagement and efficacy of the cognitive aspects of cognitive behavioural therapy (CBT) practice for this population (Taylor et al., 2008) service models and forms of delivery (Helbig and Hoyer, 2008) and with the increased prevalence of the use of e-cbt (online access) and t-cbt (telephone access) the question is raised of whether these modes of delivery present specific barriers to inclusion for this population and consequently have the potential to undermine service user autonomy in accessing mental health provision. These questions are essentially supplementary to existing physical barriers to accessibility, for example service access and environment, and consideration is given to the promotion of ethical and effective practice in response to recent World Health Organisation recommendations on disability provision (December 2011).

The paper explores this contemporary theme by first clarifying the term disability and offering a context for consideration of the theme. Second, a critique is developed of the current resurgence in the use of CBT and questions the efficacy of evidence-based practice (EBP) to support its increased usage. The paper then moves on to consider how service providers and health and social care practitioners might usefully develop provision to offer inclusive and enabling environments (EE) for this population. Finally, recommendations are offered to service providers and health and social care practitioners which aim to promote social inclusion for this population in service delivery within EU member states.

\section{Context}

The global disability prevalence is higher than previous WHO estimates, which date from the 1970 s and suggested a figure of around $10 \%$ of the global population. This global estimate for disability is on the rise due to population ageing and the rapid spread of chronic diseases, as well as improvements in the methodologies used to measure disability (World Health Organisation (WHO), 2011).

Current estimates from WHO (2011) indicate that more than one billion people in the world live with some form of disability of whom nearly 200 million experience considerable difficulties in functioning thus indicating a global prevalence closer to 20 per cent. Prevalence is also predicted to rise with the increase predominantly due to ageing populations impacted by chronic health conditions such as diabetes, cardiovascular disease, cancer and the increased diagnosis of specific mental health disorders. With such factors in mind, the WHO recently produced the World Report on Disability to provide the evidence for progressive policies and programmes to improve the lives of people with disabilities. The significance of the WHO predictions impact future service delivery planning for mental health provision in Europe and the report includes specific recommendations which suggest that commissioning bodies should:

- enable access to all mainstream systems and services;

- invest in specific programmes and services for people with disabilities;

- contribute towards a national disability strategy and plan of action;

- involve people with disabilities;

- increase public awareness and understanding;

- improve disability data collection; and

- strengthen and support research on disability (WHO, 2011).

The "EE" agenda within a mental health context is a term which has evolved over the past 20 years and has been adapted for use by a wide range of professional organisations and discussed widely in disability literature (see Swain et al., 2004). To understand attitudes toward people with disabilities, it is important to be clear as to what is meant by the word "disabled" for any discussion in relation to disability is sensitive to the definition used (Howard, 2003, p. 4 in Swain et al., 2004). Considerable academic debate has occurred over the meaning of the term and there is a wide range in variation of terminology used across EU member states by health

PAGE 104 THE JOURNAL OF MENTAL HEALTH TRAINING, EDUCATION AND PRACTICE $\mid$ VOL. 8 NO. 22013 
and social care professionals. In 2001 the WHO published its new framework for disability and health entitled the International Classification of Functioning, Disability and Health, commonly referred to as the ICF. The WHO has also developed an international standard language and a framework for the 191 United Nation's member states. Until 2001, the WHO definition of disability focused on issues of sensory ability. After ten years of work, the 2001 framework introduced a radical departure from the old assumption that disability applies to a distinct subset of people. WHO's new definition of disability aimed to establish parity between "mental" and "physical" reasons for disability and the paper uses the term to recognise the wide range of individual circumstances which may be deemed to constitute a disability, for example, those people identifying a physical, intellectual or mental health issue, or indeed a combination of several disabling conditions. The impact of the $\mathrm{WHO}$ initiative was to mainstream the experience of disability and recognise it as a universal human experience although of course such initiatives owe a debt of gratitude to the many years of campaigning by the disability movement worldwide to firmly adopt a social approach to disability The revised definition offered a construct of disability on a continuum from enablement to disablement. Personal characteristics, as well as environmental ones, were considered to be enabling or disabling depending on condition, time and setting. Disability is seen as a contextual variable, dynamic over time and circumstance. Environments may be physically accessible or inaccessible, culturally inclusive or exclusive, accommodating or unaccommodating, and supportive or unsupportive (accessing Safety.org online). These factors offer scope for significant review and of the provision and delivery of mental health services in EU member states in order to develop inclusive environments more fully.

\section{The increased use of CBT}

CBT is a generic term referring to diverse cognitive approaches to a range of behaviour and thought process modification. The purpose of CBT is to restructure individual cognitive processes and responses to perceived irrational, negative or distorted beliefs. This has the danger of decontextualising experience and locating "dysfunction" as an individual inappropriate response to environmental, structural and institutional conditions.

Although CBT has become the therapy of choice for therapeutic interventions (Meichenbaum, 1977; O'Donahue and Fisher, 2009; Wolpe, 1990), there are some significant criticisms that need to be addressed for the efficacy of intervention for people with disabilities, specifically those with mental health issues. First, this model has a faulty causality attributed to mental health difficulties. For example, symptoms such as negative self-concepts or depression are attributed to cognitive causes rather than being seen as symptoms themselves (Sun, 2009). The surface manifestation of symptoms is taken as the starting point to therapeutic intervention rather than underlying causes. Second, cognitive difficulties and mental health problems often have legitimate and reasonable causes such as trauma, abuse or neglect. To recommend a therapeutic intervention that re-orders thinking or re-framing reality rather than addressing underlying motivations does not address the need of individuals (Sun, 2009). Third, there is a questionable evidence base to support CBT. Positive self-valuation, arguably the goal of most CBT interventions, is a source of dysfunctional and maladaptive responses as much as negative thoughts and cognitions. An unrealistic and overly positive assessment of people, characteristics or situations is as disjointed as negative thoughts (Sun, 2009). Fourth, self-focused cognitive therapy does not focus on why people have overly negative thoughts when positive ones are more accurate (Sun, 2009). The difficulty of CBT is the individualising response that reorders cognition rather than changing structures, situations, environments or relationships that might have given rise to disabling environments and negative thought processes. These failings of $\mathrm{CBT}$ are particularly pertinent to barriers for $\mathrm{EE}$ and contribute to the potential exclusion for people with a variety of disabilities. CBT fosters unequal power relations between therapist and client that denies service user agendas, empowerment and disability participation rights and is a potentially manipulative and coercive form of participation (Zur, 2010).

CBT also presents political and ethical questions. For example, Pilgrim (2011) suggests CBT has accepted a "slavish" socio-economic and economistic mission. The presentation of this approach as devoid of or divorced from economic concern is highly questionable (Westbrook et al., 2011, p. iii) and has been the profitable and dominant form of contemporary therapeutic intervention. For example, Laurence (2008) quotes Andrew Samuels, a psychotherapist and 
professor at the University of Essex, who said: "What you're witnessing is a coup, a power play by a community that has suddenly found itself on the brink of corralling an enormous amount of money. Science isn't the appropriate perspective from which to look at emotional difficulties. Everyone has been seduced by CBT's apparent cheapness".

Westbrook et al. (2011) provide two further avenues of criticism. The first is the "perceived silence around questions of meaning and purpose". Any holistic understanding of people who would benefit from therapeutic intervention would need to adequately recognise the struggle and search for meaning and purpose with which most people are engaged. CBT is able to reduce these questions to maladaptive cognitive processes rather than the difficultly of reconciling meaning and purpose in a contemporary world. The second line is CBT has also been criticised for its focus on the rational conscious and not on the unconscious or creative unconscious. CBT has an over optimistic focus on the capacity, agency and conscious ability to control and influence thought (Samuels, 2011, p. iii).

Ideological difficulties have been raised by Foucault (1990) and Rose (1990), who suggest the types of knowledge, process and practices generated by specific discourses reflect the dominant cultural norms. CBT is therefore a representation of the dominant cultural practice and knowledge of individual adjustment or re-ordering to alienating social conditions. Feminists such as Brown (1994) and Miller (1976), and anti-psychiatrists such as Laing (1967) and Szasz (1970) have all criticised the adjustment to an unjust reality. CBT has the unfortunate consequences of bringing business and managerial models into therapeutic interventions which are of course attractive to commissioning bodies.

Despite the vulnerability of people with intellectual or physical disabilities to mental health problems, historically there has been a general lack of interest in or regard for the needs of this client group (Stenfert et al., 1997). In the past, therapists have been reluctant to offer individual psychotherapy to these clients because this would require them to develop close working relationships with people perceived to be unattractive because of their disability (Bender, 1993), which makes the therapeutic endeavour more demanding and the achievement of quick treatment gains more difficult (House and Loewenthal, 2011). In addition, people with intellectual disabilities may not be considered to have the cognitive abilities required to understand or benefit from CBT.

CBT has difficulties addressing internal criticism, presents potential barriers to people with various disabilities, is overly rational and cognitive, and is ideologically, economically and ethically questionable for cheap and simplistic therapeutic intervention. There is a concern that CBT can suffer misrepresentation, has been seen as a straw target, is solely conflated with randomised controlled trials, or can suffer an ill judged generic criticism of empirical methodologies. However, the critical dialogue with CBT needs to continue. CBT can also be seen as part of an emerging paradigm that is gaining dominance as the most developed type of EBP within the evaluation of mental health practice.

A growing number of medical and social science researchers criticise the EBP paradigm that was introduced during the 1990s (Cohen et al., 2003). This critique has not questioned the vital importance of basing professional practice on evidence; instead, specific issues have been addressed. The EBP uses a narrow definition of evidence, which excludes information important to professionals and to service users. It also denies the importance of tacit or implicit knowledge in the skilled professional and service users that avoid easy commodification and manipulation. Furthermore, the valuable insight from service user perspectives is discounted or excluded if it cannot be reframed or reordered as EBP. Second, the evidence collected within this paradigm is of limited usefulness when applied to individual service users, which suggest the evidence has limited external validity. A third critical issue is how the relationship between research and practice is depicted. In the conventional paradigm, emphasis is on how research findings can be made useful, and how research can be utilised in practice. In this perspective, the professional's task is to find the evidence, appraise the evidence and implement the evidence. Evidence is collected by a researcher who then presents this to the practitioners (Learmonth, 2000) whilst the knowledge generated by the practitioners seldom is the point from where research is initiated and built. Researching professionals in action is the vanguard of the emergence of a new paradigm for evidence generating practice.

PAGE $106 \mid$ THE JOURNAL OF MENTAL HEALTH TRAINING, EDUCATION AND PRACTICE $\mid$ VOL. 8 NO. 22013 
In medicine, an alternative paradigm, the evidence generating medicine paradigm (Embi et al., 2009) is in place. In this paradigm, the unidirectional translation of research into practice is integrated as one aspect of a multifaceted interaction where, "learning from every person" is a core dimension. Increasingly, the need for an alternative paradigm to EBP is recognised by social scientists, professionals and service users alike. This urgent need is propelled by the growing recognition of the importance of the social determinants of health. This methodological framework must inevitably differ from the laboratory-based paradigm for discrete clinical interventions such as medication or psychological therapies. This became evident in the recent Economic and Social Research Council study "The support priorities of multiply excluded homeless people and their compatibility with support agency agendas" (Dwyer et al., 2011) where an abductive research strategy was used begins by seeking to discover and describe the way the social world is experienced and perceived from the "inside" by developing an understanding of "insider" views (i.e. homeless people), moves across to "outsider" (i.e. key informants) accounts and finally aims to form a more comprehensive understanding of the social world by developing or amending "expert" accounts that take lay (i.e. service user) explanations seriously (Blaikie, 1993). Thus, this strategy starts with the analysis of lay explanations from both an insider and an outsider perspective and then moves on to a more theoretical/technical description of social phenomena. "Social production" means not only micro-social interactions, and macro-social forms such as socio-demographic groups and whole populations (i.e. as studied by epidemiology), but all forms of organisational social practice which create and maintain in practice the warp and weft of everyday social life. The term "health" entails mental health in the broadest sense of well-being.

Thus, health and well-being for people with disabilities experiencing mental health issues needs to be cognisant of the limitations of CBT and EBP and seek to both support and challenge the expectations of evidence-based policy and CBT practice, by grounding evidence in the activities of creative and innovative service provision; and vice versa.

\section{Developing inclusive and EE}

The paper now moves on to explore how service providers and practitioners might usefully contribute to the development of an inclusive and EE in mental health provision. In the UK, Royal College of Psychiatrists (2010) contributed to this debate by developing the EE initiative. Organisations are invited to apply for the Enabling Environments Award based on a range of core values that are considered to contribute to healthy relationships. Through a standards-based accreditation programme a service provider is supported to provide evidence that it is achieving excellence in providing a healthy relational environment for its service users. The Enabling Environments Award is a quality mark given to service providers who can demonstrate they are achieving an outstanding level of best practice in creating and sustaining a positive and effective social environment. EE are required to offer positive relationships that promote well-being for all participants and give people a sense of belonging. People are expected to be able to learn new ways of relating with a focus on growth and well-being in an environment that fosters recognition and respect to the contributions of all parties in helping relationships (Royal College of Psychiatrists, 2010). This is one example of an initiative which aims to identify features in any given setting that fosters a sense of connected belonging for the individuals involved "and suggests a process by which these principles can then be customised for specific settings" (Johnson and Haigh, 2011, p. 17). New concepts which evolved from the EE theme include the psychologically informed environment where psychotherapeutic practice is deemed central to service delivery and the psychologically informed planned environment, the latter more suited to high security and high-risk settings where planned interventions are highlighted in the approach to service delivery. These approaches strive for greater psychological awareness of a setting, humane and enlightened treatment, enhanced well-being for all involved, plus reflective practice and shared action learning in the staff team (Johnson and Haigh, 2011). Johnson and Haigh (2011) proceeded to suggest that the EE initiative signals a new approach to social psychiatry and has implications for both public mental health and social policy, commenting that: "the enabling environment approach is as broad as it is ambitious" (p. 22).

Applied to the context of mental health provision for people with disabilities it is imperative that a service provider in the EU should consider service user experiences of barriers to social inclusion 
and service user autonomy. This applies equally to modality in determining service user views of the application of, for example, CBT or alternative paradigms such as person-centred or existential psychotherapies. Equally significant in the current climate is consideration of the efficacy and appropriateness of short-term interventions for this population which are increasing prevalent in times of economic challenge. In short, commissioning bodies need to develop mental health provision which has "inclusiveness" as a core value. Achieving this balance in service delivery is seen by many organisations as a tall order and given the austerity measures that are currently impacting funding for many public services, especially in the mental health field, it is clear that the challenge for service providers and health and social care professionals is to meet the needs of the diverse range of service user needs in an inclusive and enabling way. Unfortunately, the reality is that for some people with disabilities there appear to be many barriers to social inclusion.

\section{Barriers to social inclusion}

Service providers are encouraged to develop approaches to attracting and maintaining contact with service users presenting with common mental health problems (Grant et al., 2011). This study found that significant numbers of service users failed to opt-in, attend the first appointment or subsequently dropped out during therapy. The study also found that there were no differences in levels of opt-in between the application of CBT and person-centred therapy and that that those from the most deprived areas were less likely to opt-in. In circumstances where screening processes are utilised, for example when using t-cbt and e-cbt to ascertain eligibility of access to face-to-face provision, there is the potential to inhibit access to provision for some service users and particularly so for some service users who have a disability. For example, for some elderly service users with a disability there may be a reluctance to use telephone and online resources as this may be physically or culturally challenging for them. In order to attract and maintain contact with service users, quality controls would need to be considered to establish and maintain contact with those service users who are more reluctant to engage. Oliver (1996) commented on the dangers of the denial of inclusion for this population and since this time EU directives have been developed to promote senvice user autonomy and values of inclusion. The WHO recommendations on disability provision (December 2011) provide a framework around which to develop EE within the mental health sector. This is a particularly pressing issue for this population in the economic context of ongoing austerity measures in many EU member states. Inclusion Europe, a Brussels based pressure group promoting inclusion issues of people in Europe with intellectual disabilities, comment that many people with intellectual disabilities cannot participate fully in society and that many experience social exclusion and discrimination as a result (Inclusion Europe, 2012). This theme is a common message from disability pressure groups and applied to a mental health context the issue becomes one of equal access to services for this population.

\section{Recommendations}

This discussion of factors pertinent to developing inclusive environments in mental health provision for people with disabilities offers the following recommendations for consideration by service providers, commissioning bodies and health and social care practitioners:

1. a call for further evidence-based research of service user views to measure whether CBT and short-term interventions are responding in a socially inclusive and responsive manner to this population;

2. a need for specific education, training and continuing professional development for health and social care professionals to keep up to date with developments in this field;

3. consideration of the theoretical orientation of service delivery and the appropriateness of this for some service users;

4. consideration of the EE's agenda to ascertain whether inclusiveness is being achieved for service users who declare a disability (Appendix offers the criteria required by the Royal College of Psychiatrists, 2010);

5. consideration of service access issues particularly at the point of delivery and especially where non-face-to-face provision is the primary point of contact; and

PAGE 108 THE JOURNAL OF MENTAL HEALTH TRAINING, EDUCATION AND PRACTICE $\mid$ VOL. 8 NO. 22013 
6. consideration of the mode of service delivery and whether these present any physical, cultural or social barriers to inclusion.

\section{Conclusion}

Given that CBT as a method has more recently achieved the scientific "gold standard" as a preferred method of delivery, the authors offer the question as to whether this model and approach can respond effectively to all groups within our society. Of particular concern are potential barriers to accessibility and social inclusion such as the increased use of $\mathrm{t}$-cbt and e-cbt as a method of screening service users. These approaches have the potential to undermine a service provider's commitment to the development of social inclusion for this population and only by conducting a full evaluation of service user views and experiences can a service ascertain whether it is offering an inclusive and EE.

The combination of the contemporary situation of CBT and EBP present significant challenges to develop autonomy and social inclusion for people with disabilities in Europe. The promotion of independence and personal responsibility is potentially reduced by CBT interventions. The use of a cost-effective, simplistic and short-term therapy errs on a favourable response to economic austerity in the current climate rather than promoting values of inclusion, autonomy and meaningful, value based, supportive interventions. This is particularly relevant to service delivery issues where social inclusion needs to be balanced against the wider challenges of delivery in the current economic climate.

\section{Glossary \\ CBT cognitive behavioural therapy \\ EBP evidence-based practice \\ EE enabling environments}

\section{References}

Bender, M. (1993), "The unoffered chair: the history of therapeutic disdain towards people with a learning difficulty", Clinical Psychology Forum, Vol. 54, pp. 7-12.

Blaikie, N. (1993), Approaches to Social Enquiry, Polity Press, Oxford.

Brown, L.S. (1994), Subversive Dialogues: Theory in Feminist Therapy, Basic Books, New York, NY.

Cohen, A.M., Stavri, P.Z. and Hersh, W.R. (2003), "A categorization and analysis of the criticisms of evidence-based medicine”, International Journal of Medical Information, Vol. 73 No. 1, pp. 35-43.

Dwyer, P., Bowpitt, G., Sundin, E. and Weinstein, M. (2011), "The support priorities of multiply excluded homeless people and their compatibility with support agency agendas", ESRC End of Award Report, RES188-25-0001, ESRC, 2010, Swindon.

Embi, P.J., Payne, P.R., Weiner, M. and Hersh, W. (2009), "Evidence generating medicine: integrating research and practice to accelerate clinical and translational science", American Medical Informatics Association, AMIA Annual Symposium Proceedings, San Francisco, CA.

Foucault, M. (1990), The Use of Pleasure: The History of Sexuality, Vol. 2, Random House, New York, NY.

Grant, K., McMeekin, E., Jamieson, R., Fairfull, A., Miller, C. and White, J. (2011), "Individual therapy attrition rates in a low-intensity service: a comparison of cognitive behavioural and person-centred therapies and the impact of deprivation greater glasgow and clyde NHS, Scotland", available at: http://journals. cambridge.org/action/displayAbstract?fromPage $=$ online\&aid $=8488230 \&$ fulltextType $=$ CR\&fileld $=$ S13 52465811000476 (accessed 28 May 2012).

Helbig, S. and Hoyer, J. (2008), "Service models and forms of delivery what do patients do before it starts? Coping with mental health problems on a CBT waiting list", The Cognitive Behaviour Therapist, Vol. 1, pp. 45-54.

House, R. and Loewenthal, D. (2011), "An exploration of the criticism of CBT'”, in Westbrook, D., Kennerley, H., and Kirk, J. (Eds), An Introduction to Cognitive Behavioural Therapy: Skills and Application, Sage, London, pp. 8-12. 
Inclusion Europe (2012), "Title of newsletter: e-Include", available at: www.e-include.eu/en/articles/66mainstream-social-services-and-persons-with-intellectual-disabilities (accessed 30 May 2012).

Johnson, R. and Haigh, C. (2011), "Social psychiatry and social policy for the 21st century: new concepts for new need - the enabling environments initiative", Mental Health and Social Inclusion, Vol. 15 No. 1, pp. 17-23.

Laing, R.D. (1967), The Politics of Experience and the Bird of Paradise, Penguin, Harmondsworth.

Laurence, J. (2008), "The big question: can cognitive behavioural therapy help people with eating disorders?", The Independent, Tuesday 16 December.

Learmonth, A.M. (2000), "Utilising research in practice and generating evidence from practice", Health Education Research, Vol. 15 No. 6, pp. 742-56.

Meichenbaum, D. (1977), Cognitive Behaviour Modification: An Integrated Approach, Plenum, New York, NY.

Miller, J.B. (1976), Toward a New Psychology of Women, Beacon Press, Boston, MA.

O'Donahue, W. and Fisher, J. (2009), Cognitive Behaviour Therapy: Applying Empirically Supported Techniques in Your Practice, 2nd ed., Wiley, London.

Oliver, M. (1996), Understanding Disability - From Theory to Practice, Palgrave Macmillan, Basingstoke.

Pilgrim, D. (2011), "Reading happiness: CBT and the layard thesis", in Westbrook, D., Kennerley, H. and Kirk, J. (Eds), An Introduction to Cognitive Behavioural Therapy: Skills and Application, Sage, London, pp. 256-68.

Rose, N. (1990), Governing the Soul: The Shaping of the Private Self, Routledge, London.

(The) Royal College of Psychiatrists (2010), "What is the enabling environments award?", available at: www.rcpsych.ac.uk/quality/qualityandaccreditation/enablingenvironments.aspx (accessed 28 May 2012).

Samuels, A. (2011), "Forward", in Westbrook, D., Kennerley, H. and Kirk, J. (Eds), An Introduction to Cognitive Behavioural Therapy: Skills and Application, Sage, London, pp. iii-iiv.

Stenfert, K.B., Dagnan, D. and Loumidis, K. (Eds) (1997), Cognitive-Behaviour Therapy for People with Learning Disabilities, Routledge, London.

Sun, K. (2009), "Four drawbacks of cognitive therapy, the justice and responsibility league", available at: www.psychologytoday.com/blog/the-justice-and-responsibility-league/200903/four-drawbacks-cognitivetherapy (accessed 15 April 2012).

Swain, J., French, S., Barnes, C. and Thomas, C. (2004), Disabling Barriers - Enabling Environments, 2nd ed., Sage Publications, London.

Szasz, T. (1970), Ideology and Insanity: Essays on the Psychiatric Dehumanization of Man, Anchor Books, Garden City, NY.

Taylor, J.L., Lindsay, W.R. and Willer, P. (2008), "CBT for people with intellectual disabilities: emerging evidence, cognitive ability and IQ effects”, Behavioural and Cognitive Psychotherapy, Vol. 36 No. 6, pp. 723-33.

Westbrook, D., Kennerley, H. and Kirk, J. (2011), An Introduction to Cognitive Behavioural Therapy: Skills and Application, Sage, London.

Wolpe, J. (1990), The Practice of Behaviour Therapy, 4th ed., Permagon, New York, NY.

World Health Organisation (WHO) (2011), "Report on disability December 2011", available at: www.who.int/ disabilities/world_report/2011/report/en/index.html (accessed 14 December 2011).

Zur, O. (2010), "Power in psychotherapy and counseling", available at: www.zurinstitute.com/ power_in_therapy.html (accessed 16 October 2012).

\section{Further reading}

Accessing Safety Initiative (2010), "World Health Organisation's definition of disability", available at: www.accessingsafety.org/index.php/main/main_menu/understanding_disability/a_new_definition/world_health_ organization_s_definition_of_disability (accessed 30 May 2012). 


\section{Appendix}

The Royal College of Psychiatrists (2010)

Criteria which contribute towards the Enabling Environments (EE) Award

BELONGING

The nature and quality of relationships are of primary importance

BOUNDARIES

There are expectations of behaviour and processes to maintain and review them

COMMUNICATION

It is recognised that people communicate in different ways

DEVELOPMENT

There are opportunities to be spontaneous and try new things

INVOLVEMENT

Everyone shares responsibility for the environment

SAFETY

Support is available for everyone

STRUCTURE

Engagement and purposeful activity is actively encouraged

EMPOWERMENT

Power and authority are open to discussion

LEADERSHIP

Leadership takes responsibility for the environment being enabling

OPENNESS

External relationships are sought and valued

\section{Corresponding authors}

Graham Whitehead can be contacted at: graham.whitehead@ntu.ac.uk

Adam Barnard can be contacted at: adam.barnard@ntu.ac.uk

To purchase reprints of this article please e-mail: reprints@emeraldinsight.com Or visit our web site for further details: www.emeraldinsight.com/reprints 